\title{
Early Intervention in Any Diabete Undiagnosed Patient Suffered from Ocular and Cardiovascular Diseases in Cardiology
}

\author{
Anvoh Koutoua Yves Blanchard ${ }^{1,2, *}$, Agbo Adouko Edit $\mathbf{H}^{\mathbf{1}}$, Koko Anoma Casimir ${ }^{3}$, \\ Diabagaté Hadja Fatim ${ }^{1,2}$, Houroupou Mbambai Jacques ${ }^{4}$, Brou Kouakou ${ }^{1}$ \\ ${ }^{1}$ Department of Food Sciences and Technology, Nangui Abrogoua University, Ivory Coast \\ ${ }^{2}$ Dietetic Service of Cardiology Institute of Abidjan, Ivory Coast \\ ${ }^{3}$ Department of Agroforestry, Jean Lorougnon Guede University, Ivory Coast \\ ${ }^{4}$ Centre Evangélique Pour l'Encadrement Nutritionnel (CEVANUTRI), Tchad
}

Received November 19, 2018; Revised January 7, 2019; Accepted January 17, 2019

Copyright $\bigcirc 2019$ by authors, all rights reserved. Authors agree that this article remains permanently open access under the terms of the Creative Commons Attribution License 4.0 International License

\begin{abstract}
Glycosylated haemoglobin (HbAlc) is a form of haemoglobin that is measured primarily to identify the average plasma blood glucose concentration prolonged periods previous 120 days. Cardiologist used to treat patients generally when glucose level is over $1.26 \mathrm{~g} / 1$. Unfortunately, Haemoglobin Alc was seldom controlled. The objective of this study was to detect persons with type 2 diabetes risks by the correlation between $\mathrm{HbAlc}$ levels and random glucose one and propose a good management by lifestyles. Methods: This descriptive study included 216 patients selected randomly with cardiovascular complications and ocular diseases but none diabetes diagnosed. Glycaemia and $\mathrm{HbA1c}$ measurement were done. Results: All the patients were not diabetes diagnosed. There was a low correlation between the blood glucose levels and the glycated haemoglobin $\mathrm{r}=0.2761$ ). Hypocaloric diet applied to type 2 diabetes management decreased glycaemia and Haemoglobin Hbalc. The decreasing of Hbalc was estimated from $14 \%$ to $17 \%$ of the initial values. Conclusions: Glycaemia must not only be considered to manage cardiovascular complications at Cardiology Institute of Abidjan. The contribution of hypocaloric diet with high vegetable and one fruit intake a day lead to better type 2 diabetes management.
\end{abstract}

Keywords Heart Diseases, Glycaemia, Haemoglobin Alc, Correlation, Diabetes Fruits

\section{Introduction}

The number and prevalence of people with diabetes are increased rapidly The International Diabetes Federation (IFD) estimates that there were 381.8 million people with diabetes in 2013 and this value should increase and reach 591.9 million by 2025 [1]. In our country, no study showed national diabetes prevalence rate. When this disease is not well supported, complications rise that threaten health and endanger life. So, all types of Diabetes can lead to complications in many parts of the body and can increase the overall risks of dying prematurely [2]. Possible complications include heart attack, stroke, kidney failure, leg amputation and loss of vision. In addition to these traditional complications describe above, diabetes has been associated with increased rates of specific cancers [3], increased rates of physical and cognitive disability [4]. Diabetes and higher-than-optimal blood glucose all together were responsible for 3.7 million deaths in 2014.

In order to reduce mortality from diabetes and improve outcomes, access to affordable treatment is critical. But, the management of diabetes is very expensive. Based on cost estimated from a recent systematic review, it has been estimated that the direct annual cost of diabetes in the world is more US\$ 827 billion [5]. The proportion of undiagnosed and untreated type 2 diabetes varies widely [6] and is higher overall in lower-income countries where its effects is marked [7].

The best way to manage diabetes is prevention. American Diabetes Associations (ADA) recommends more and more that patients with newly diagnosed type 2 diabetes be treated with pharmacotherapy as well as lifestyle changes [8]. In addition, several studies show advantage of diets on patients with newly diagnosed type 2 diabetes. In opposition to the type 1 diabetes, which treatment needs obviously insulin, the type 2 diabetes may 
remain undetected for many years, during which time complications may develop. A lifestyle changes may be very important [9]. So, preventing diabetes by diagnosing pre-diabetics could be an important way to stop diabetes prevalence increasing.

In Cardiology Institute of Abidjan, many patients coming for heart diseases have a normal blood glucose level but suffer from retinopathies, doubtless related to undiagnosed diabetes. As diabetes affect heart and eyes, it is important to determine among these patients, potential pre-diabetics by controlling Haemoglobin A1c which is an essential way to monitor long term glycaemic control [10].

This study was conducted in order to detect and prevent type 2 diabetes by establishing the correlation between glucose levels and haemoglobin Alc and to propose diet with local dishes to patients at Cardiology Institute of Abidjan (Côte d'Ivoire).

\section{Research Design and methods}

This study was conducted at Cardiology Institute of Abidjan (Côte d'Ivoire) in 2017. During 6 months dietary trials were proposed to new type 2 diabetes with modification of their habitual diets when necessary.

\section{Screening Phase}

Two hundred and sixteen (216) volunteers with newly type 2 diabetes diagnosed aged $55.83 \pm$

8 years participate to the study. Their blood glucose levels averaged $1.2 \pm 0.3 \mathrm{~g} / 1$ with $\mathrm{HbAlc}$ rate ranged between 6 and $8 \%$. These patients had never been treated with antihyperglycemic drugs from the clinical practices.

\section{Dietary Interventions}

Recommendations were delivered during one-to one consultation sessions. Volunteers were asked about their habitual diets. Diets mistake were explained and advises were given to them during 30 to 45 minutes. The nutritionist, in consultation with each volunteer, drew up meal programs for the study period and patients noted any deviation from the original program.

The nutritionist gave dietary advice to participant in order to avoid stressful diets. They met 2 weeks after the first consultation for the control. Any portion size was indicated. They had choice among diet proposed at breakfast and lunch, but they should follow strictly the dinner diet day by day. Only men were authorised to add 40 $\mathrm{g}$ of bread to vegetable soup on Tuesday and Friday when required. It was a hypocaloric diet especially in the evening (Table 1).

The diet included low saturated fats, and more breads (morning and evening), roots tubers, vegetables and fish. It also had less red meat and more poultry. The participants were also taught to prepare their own meals or no.

In addition, fruits consumption and fruit consumption time were studied. The patients was divided in 3 subgroups. In the first subgroup, volunteers were assigned to eat more than 3 fruits without time indication; in the second subgroup, patients were advised to eat more than 3 fruits during 3 first months et limit to one fruits during the 3 other months (group 2) and the last subgroup was reserved to patients who ate only one fruit per day before 17:00 (group 3).

\section{Meal to Forbid}

Some foods were forbidden such as mango, pineapple, grape fruit, sodas, jus, and beer.

\section{None Dietary Interventions}

Although walking was encouraged during 45 minutes, patients were allowed to choose other types of moderate-intensity physical activity twice or 3 times a week.

Table 1. Example of typical food intake during our study

\begin{tabular}{|c|c|}
\hline Designation & Menus \\
\hline breakfast & $\begin{array}{l}40 \mathrm{~g} \text { bread }+ \text { eggs } \\
40 \mathrm{~g} \text { bread }+ \text { paste fish } \\
40 \mathrm{~g} \text { bread }+ \text { the } / \text { coffee } / \text { cocoa }+ \text { sweetener } \\
40 \mathrm{~g} \text { bread }+ \text { cheese } \\
40 \mathrm{~g} \text { bread }+ \text { margarine }\end{array}$ \\
\hline lunch & $\begin{array}{l}\text { Rice }+ \text { leafy vegetable sauce }+ \text { fresh fish } \\
\text { Attieke }+ \text { vegetable sauce }+ \text { fresh fish } / \text { meat } \\
\text { Placali }+ \text { leafy vegetale sauce }+ \text { meat/fish } \\
\text { Maize paste }+ \text { vegetable sauce } \\
\text { Pounded banana/yam +okra sauce (once a week) }\end{array}$ \\
\hline dinner & $\begin{array}{l}\text { Green bean }+40 \text { bread (Monday) } \\
\text { Vegetable soup }+ \text { fish (Tuesday) } \\
\text { Vegetable lettuce }+2 \text { eggs (Wednesday) } \\
\text { Green peas }+ \text { fish (Thursday) } \\
\text { Vegetable mix soup }+ \text { fish }+40 \mathrm{~g} \text { bread (Friday) } \\
\text { Grilled fish +vegetable }+40 \text { g bread (Saturday) } \\
\text { Diced mixed vegetables }+ \text { fish (Sunday) }\end{array}$ \\
\hline
\end{tabular}

\section{Glycaemic Control}

Analyses were led each 2 months and half (75 days). First samples were made at $\mathrm{T}_{0}$. Second samples were made 75 days later and this date was mentioned $T_{0}$ then $T_{1}$ and $\mathrm{T}_{2}$ Capillary blood samples were analysed for glucose by a glucose-oxidase method. Assays were performed in the hospital's chemistry laboratory. HbAlc levels were determined with high pressure liquid chromatography by using Nycocard Reader II Alere Technologia As, Oslo Norway, SN94083).

\section{Statistical Analysis}

The statistical analysis was performed using STATA 
version 12.0. Pearson's correlation was applied to find out correlation between the glycated haemoglobin levels and the random blood glucose levels in undiagnosed Cardiology patients with ocular affections. Results were plotted on simple scatter plot and $\mathrm{p}<0.05$ was considered significant.

\section{Results}

A total of 216 patients were included in the study. A simple scatter graph plotted between levels of random blood glucose and glycated haemoglobin rate shows correlation between both parameters. Figure1 shows a correlation between the levels blood and Hbalc of whole patients. The correlation was low $(r=0.2538)$ and the difference was significant $(\mathrm{p}=0.0002)$.

On figure 2 , there was a weak correlation between blood glucose and hemoglobin $(\mathrm{r}=0.2761)$ for patients in group 1 ; however, there is a significant statistical difference $(\mathrm{p}=$ 0.0105). On the third figure representing the patients of group 2, there is also a weak correlation between blood glucose and Hbalc $(\mathrm{r}=0.2520)$ but the difference is significant $(\mathrm{p}=0.0148)$ (figure 3$)$.

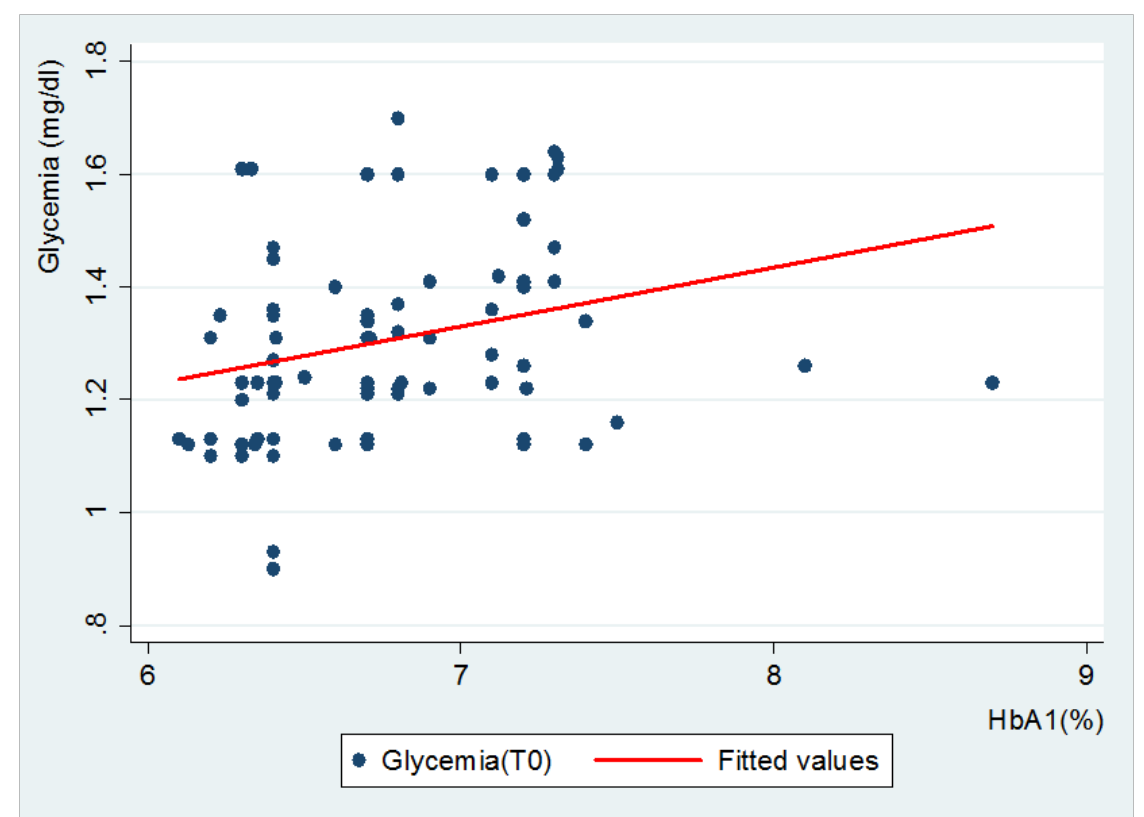

Figure 1. Simple scatter graph between random blood glucose $(\mathrm{mg} / \mathrm{dl})$ and glycated haemoglobin at $\mathrm{T}_{0}$ for both groups. ( $\left.\mathrm{r}=0.2538\right)$

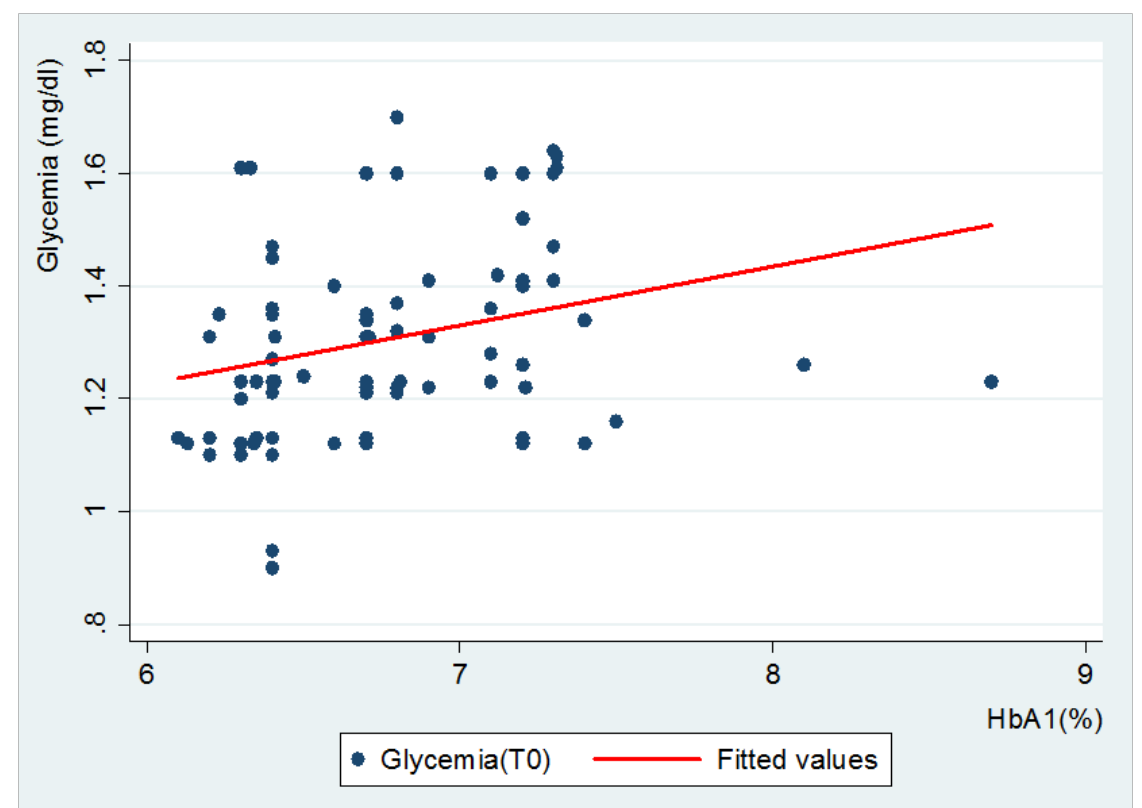

Figure 2. Simple scatter graph between random blood glucose (mg/dl) and glycated haemoglobin at T0for group1. ( $(\mathrm{r}=0.2761)$ 


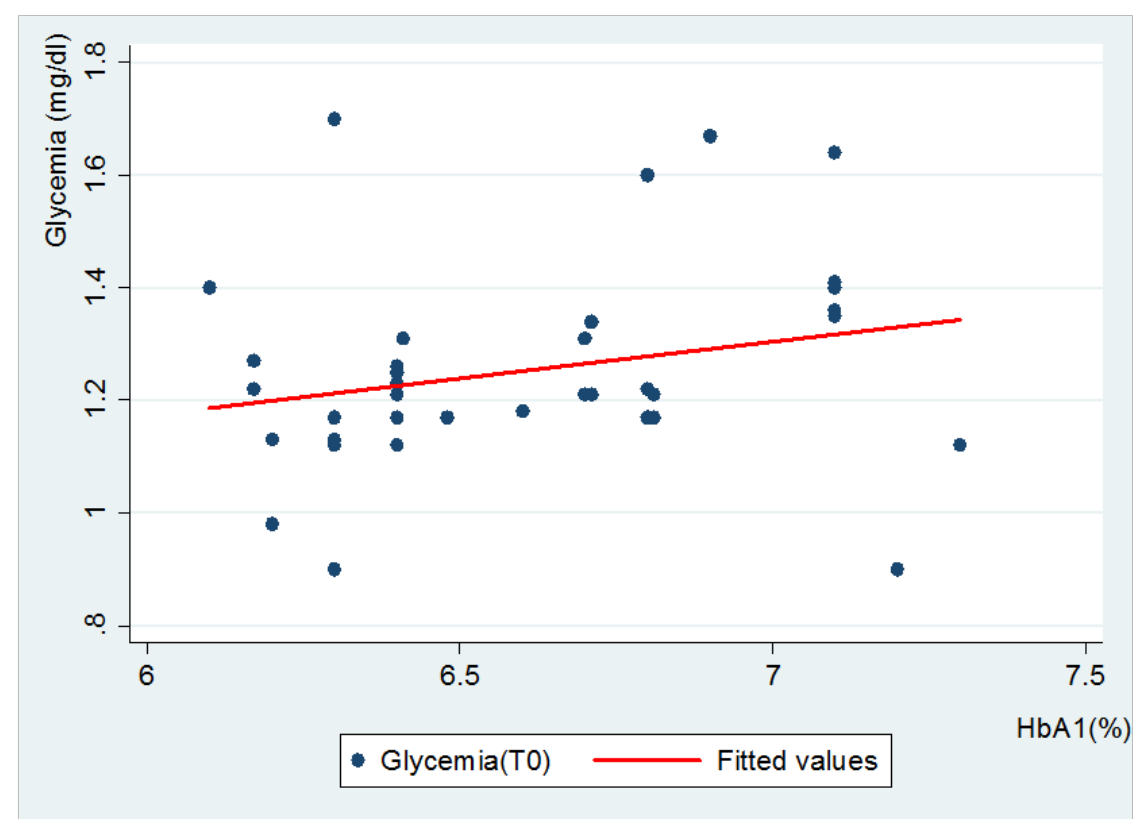

Figure 3. Simple scatter graph between random blood glucose $(\mathrm{mg} / \mathrm{dl})$ and glycated haemoglobin at $\mathrm{T}_{0}$ for group $2(\mathrm{r}=0.2520)$.

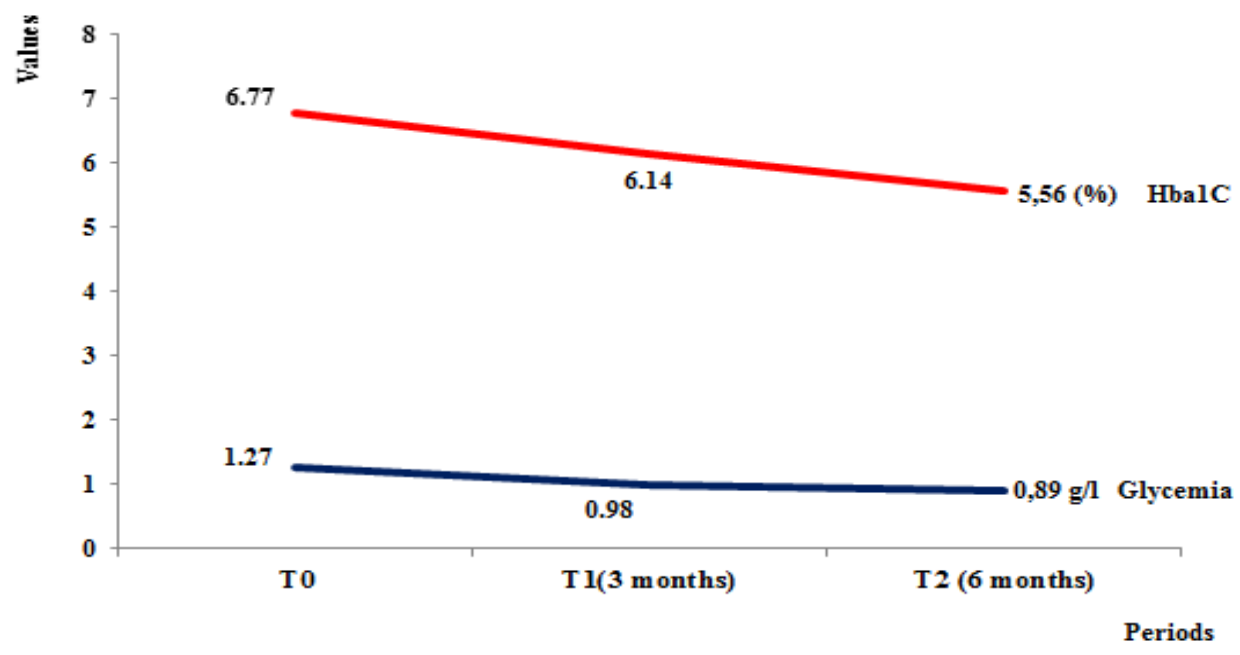

Figure 4. Blood glucose and glycated haemoglobin graph during the study

This figure shows the results of glycaemia for whole groups after 6 months of diets management. A significant decrease of bloods glucose levels was observed at the end of our study. However, results are more beneficial $(0.72 \mathrm{~g} / \mathrm{l})$ for patients in group 3 who reduced fruits consumption than of group 1 with $1.04 \pm 0.67 \mathrm{~g} / 1$ as final results. A significant decrease of bloods glucose levels was observed at the end of our study. However, results are more beneficial $(0.72 \mathrm{~g} / \mathrm{l})$ for patients in group 3 who reduced fruits consumption than of group 1 with $1.04 \pm 0.67 \mathrm{~g} / 1$ as final results. A significant difference was also observed between the results of group 1 and both group 2 and 3 .

Figure 4 also presents the average of glycated haemoglobin. There was a tendency for these measurements. Significant reduction in glycated haemoglobin was observed at the end of our study.
Differences between final values were not observed. From the beginning to the end of our study, there was a drop averaging 14 to $17 \%$ on $\mathrm{HbAlc}$ initial values.

\section{Discussion}

The discussion will focus on two axes: the first axe will deal with correlation between glycaemia and glycated haemoglobin while the second part will be devoted to early diabetes management.

\section{Diabetes Detection from Patients with Heart Diseases}

There was a correlation between glycaemia and glycated hemoglobin. However this correlation was low for patients 
who have fruits limitation (one fruit a day). The low correlation between blood glucose levels and the rate of hemoglobinAlc means that some patients may have a blood glucose of $0.9 \mathrm{~g} / 1$ with glycated hemoglobin more than $7 \%$.

The low correlation between blood glucose and Hbalc could be linked to the diversity of our local diets and the variability of Hbalc according to race and ethnicity [11]. Indeed, contrarily to high-incomes countries which have general nutritional rules, diets in low-incomes countries are highly variable. This diversity is related to ethnic groups, living conditions and crops. To this, it will be necessary to add the effects of higher A1C levels among blacks [12-13].

These authors have shown that blacks were more sensible to $\mathrm{HbA1C}$. This weak correlation between $\mathrm{HbA1c}$ levels and blood glucose one was not similar with the results of patients in type 2 Diabetes with medication [14-15]. There was a strong correlation between the same parameters.

This study had also shown that there are many patients with type 2 diabetes undiagnosed in Cote d'Ivoire as well as in other low income countries which were estimated to $83.8 \%$ in 2011[16]. Moreover, to establish a good treatment for patients in cardiology with ocular affections, glycated haemoglobin should necessary be controlled in addition to glycaemia. This could also help to perform cardiology regarding therapy. Patricians in Cardiology should pay more attention with patients with retinopathy and whom were submit to no fruit limitation. For these patients, the initial glucose level values were variable although their $\mathrm{HbAlc}$ was higher. If this higher $\mathrm{AlC}$ haemoglobin remains undetected for many years, patients should develop complications [17]. Among the patients in group 1, the correlation between glycaemia and Hbalc is very weak. This observation leads to question about fruit consumption. Increasing individual fruits and vegetable consumptions from 400 to $600 \mathrm{~g}$ a day was recommended to prevent premature death in New Zealand, Australia and the EU [18]. It is therefore important to specify the number of fruits and vegetables and, above all, to show that there is a difference between fruits and vegetable. Both foods have high fibers and antioxidants capacities. Contrary to vegetable, fruits contain fructose, glucose and sucrose in various combinations and, if these free sugars are in high concentrations they should be restricted in the diet of diabetic patients [19]. High fruits consumption increases blood sugar, which could justify the ever-increasing numbers of people diagnosed with diabetes in the world.

\section{Early Type 2 Diabetes Management}

The present study confirms the beneficial effects of hypocaloric diets (carbohydrate reducing diets) in the treatments of type 2 diabetes. Our results show a clear improvement in the level of glycaemia and glycated haemoglobin after 6 months of nutritional monitoring. The carbohydrate reducing diets were important because the amount of carbohydrate is the major determinant for blood glucose response [20]. Sugar reduction concerns both fruit sugar and cereal grains and feculent. These foods were forbidden in the evening. These modifications reduced the risk of progression to type 2 Diabetes. Patients with fruits limitation had lower glycated haemoglobin than those with more than one fruit consumption. The relative higher concentration of blood glucose may be attributed to the higher fruits intake, because fruits are rich in sugar [21]. This author showed the variability of sugar in 29 dried date palm varieties ranging from 61.7 to 78.6 per cent in Asia. This result was confirmed in Nigeria in Africa [22]. It is therefore necessary to specify the number of vegetables and the number of fruits in the concept of 5 fruits and vegetables but not to have higher fruit intake. This precision is very important, because, in low-income-countries such as those of Africa, vegetables such as leafy vegetable are produced [23-24]. These legumes and vegetables are rich in nutrients and represent a vegetable-based sauce [25-26]. Vegetable are used to be combined in carbohydrate dishes up to $250 \mathrm{~g}$ a day per person in Nigeria [27]. So, people should be encouraged to increase their vegetable soup or sauce consumption with only one fruit (from100 to $150 \mathrm{~g}$ ) to be in concordance with World Health Organization (WHO).

\section{Conclusions}

Levels of blood glucose can't give a clear idea about glycaemic for undiagnosed patients with type 2 Diabetes. Our study shown a low correlation glycemia and $\mathrm{HbA} 1 \mathrm{c}$. Several patients with heart disease are undiagnosed diabetic. If glycated haemoglobin control was earlier made, they could reach out diabetes by a good established diet and reducing fruit consumption. Haemoglobin A1C should be systematically controlled for all patients with heart and ocular diseases. It would be rather useful to recommend the consumption of one fruit a day before $5.00 \mathrm{pm}$ and to increase that variables vegetables.

\section{Competing Interests}

The authors declare that they have no competing interests.

\section{REFERENCES}

[1] L. Guariguata L., D.R. Whiting, I. Hambleton, J. Beagley, U. Linnenkamp, J.E. Shaw. Global estimates of diabetes prevalence for 2013 and projections for 2035,Diabetes Research and Clinical Practice, 106(2): 14-16, 2004. 
[2] C.M.Alexander, S. Antonello, C.T. (A.S.C.P.), C. Heggan. and R. A. Calder, Cholesterol management in the patient with diabetes, Practical Diabetology 21:21-28, 2002.

[3] B.C. Jin, W. M.Hyong, H.P.Young, J.B.Wong, J.C. Hyuk, H. Sung-Hoo, Y.L. Ji Y., W.K. Sae, H. Kyung-Do and H. U-Syn (2016). The Impact of Diabetes on the Risk of Prostate Cancer Development according to Body Mass Index: A 10-year Nationwide Cohort Study. Journal of cancer 7(14): 2061-2066, 2016.

[4] E. Wong, K. Backholer, E. Gearon, J. Harding, R. Freak-Poli and C. Stevenson, Diabetes and risk of physical disability in adults: a systematic review and meta-analysis, Lancet Diabetes Endocrinology 1(2): 106-114, 2013,

[5] T. Seuring T., Archangelidi and M. Suhrcke, The economic costs of type 2 diabetes: A global systematic review, PharmacoEconomics 33(8): 811-831, 2015.

[6] E. Gakidou, L.Mallinger, J. Abbott-Klafter, R. Guerrero, S. Villalpando, R. L. Ridaura, C. J. L. Murray. Management of diabetes and associated cardiovascular risk factors in seven countries: A comparison of data from national health examination surveys. Bulletin of the World Health Organization 89(3): 172-183, (2011).

[7] C.M. Smith-Spangler, J. Bhattacharya and JD Goldhaber-Fiebert. Diabetes, its treatment, and catastrophic medical spending in 35 developing countries.Diabetes Care 35(2): 319-326, (2012).

[8] D.M. Nathan., J. Kuenen, R. Borg, H. Zheng, D. Schoenfeld and R.J. Heine. .A1C Derived average Glucose study Group. Translating the $\mathrm{A} 1 \mathrm{C}$ assay into estimated blood glucose values. Diabetes Care 31: 1473-1478, (2008).

[9] K. Yamaoka and T. Tango. Efficacy of lifestyle education to prevent type 2 diabetes: a meta-analysis of randomized controlled trials. Diabetes Care 28:2780-2786, (2005).

[10] D.B.Sacks, D.E. Bruns, D.E. Goldestein, N.K. Maclaren, J.M. MacDonald and M. Parott. Guidelines and recommendations for laboratory analysis in the diagnosis and management of diabetes mellitus.Clinical Chemistry 48:436-472, (2002).

[11] J.K. Kirk, R.B. Jr. D’Agostino, R. A. Bell. Disparity in HbAlc levels between African- American and nonHispanic white adults with diabetes: a meta-analysis. Diabetes Care; 29: 2130-2136, (2006).

[12] K. Sikaris, B.Sc., M.B.B.S., FRCPA, FAACB. The Correlation of HemoglobinA1c to Blood Glucose. Journal of Diabetes Science and Technology 3(3): 429-438, (2009).

[13] S. Colagiuri, C. M. Lee, T.Y. Wong et al. K. Glycemic thresholds for diabetes-specific retinopathy: implications for diagnostic criteria for diabetes. Diabetes Care; 34: 145-150, (2011).

[14] H. Nasir, K. Shah, G. Saima, A. Saleem and H. Saad. Correlation between glycated haemoglobin levels and random blood glucose.Journal of Ayub Medical College Abbottabad 25 (1-2): 86-88, (2013).

[15] J. Pomerleau, K. Lock and Mc. Kee. The burden of cardiovascular disease and cancer attributable to low fruit and vegetable intake in the European Union: differences between old and new member states. Public Health Nutrition 9(5): 575-583, (2006).
[16] N. Nahar, S. Rahman, M. Mosilihuzzaman. Analysis of Carbohydrates in Seven Edible Fruits of Bangladesh.Journal Science Food Agriculture 51: 185 - 192, (1990).

[17] K. N. Englyst, S. Liu and H. N. Englyst. Nutritional characterization and measurement of dietary carbohydrates.European Journal of Clinical Nutrition 61: S19-S39, (2007).

[18] L. Charlotte Edwardson, J. Laura Gray, Thomas Yates, R. Shuan Barber, Kamlesh Khunti, J. Melanie Davies. Detection and Early lifestyle intervention in those at risk of type 2 Diabetes.European Diabetes Journal 2:48-57, (2004).

[19] T. Yates, M.J. Davies, J. Henson, J. Troughton, C. Edwardson, L. J. Gray and K. Khunti. Walking away from the type 2 diabetes: trial protocol of a cluster randomized controlled trial evaluating a structured education programme in those at high risk of developing 2 type diabetes. $B M C$ Family Practice 13:46, (2012).

[20] Omowunmi Sola Agboola and Ayoade Lateef Adejumo. Nutritional Composition of the Fruit of the Nigerian Wild Date Palm, Phoenix dactylifera.World Journal of Dairy and Food Sciences 8 (2): 196-200, (2013).

[21] E. Strandhagen, P-O Hansson, I. Bosaeus, B. Isaksson and H. Eriksson. High fruit intake may reduce mortality among middle-age and elderly men. The Study of men born in 1913.European Journal of clinical nutrition 54: 337-341, (2000).

[22] C.R. Zhang, S.A. Aldosari, P.S.P.V. Vidyasagar, P. Shukla and M. G. Nair. Determination of the variability of sugars in date fruit varieties.Journal of Plantations Crops. 43 (1) 53-61, (2015).

[23] P.M. Maundu, E.I. Njiro, J.A. Chweya, J.K. Imungi and E.N Seme. The Kenyan case study. In: Chweya, J.A. and Eyzaguirre, P.B. (eds.). The Biodiversity of Traditional Leafy Vegetables, Rome, IPGRI, pp. 51-84, (1999).

[24] J. Bealey, L. Garigata, A. M. Ayesha, C. Weil, Global estimates of undiagnosed diabetes in adults. Diabetes Research and Clinical Practice 103: 150-160, (2014).

[25] J.B. Pele et Le Berre. Les Aliments d'Origine Végétale au Cameroun. ORSTOM, le Cameroun agricole, pastoral et forestier, $\mathrm{N}^{\circ} 110$, pp 49-67, (1967).

[26] J. Gockowski, J. Mbazo'o, G. Mbah and T.F. Moulende. African traditional leafy vegetables and the urban and peri-urban poor. Food policy.28 (3). 221-235, (2003).

[27] N. E. Chubike, J. C. Okaka and E.C. Okoli. Evaluation of vegetable consumption in South Eastern Nigeria. International Journal of Nutrition and Metabolism.Vol. 5(4), pp. 57-60, (2013) 